\title{
Forming of titanium and titanium alloy miniature-cylinders by electrical-field activated powder sintering and forming
}

\author{
Muhammad Zulkiplia, Yi Qin, Kunlan Huang, Hasan Hijji, Yihui Zhao, and Jie Zhao \\ Department of Design, Manufacture \& Engineering Management (DMEM), University of Strathclyde, \\ 75 Montrose Street, Glasgow G1 1XJ, UK
}

\begin{abstract}
As demands on miniature products increase significantly, a rapid process and production system for high-throughput, highly flexible and cost-efficient volume production of miniaturised components made from a wide range of materials is needed. A novel and electrical-field-activated sintering and forming process shows the potential to produce solid parts from powder material without any binder. Using titanium (Ti) and titanium alloy (90Ti10Sn) powder material, several processing parameters have been investigated, such as pressure, heating rate, heating temperature and holding time, which helped to contribute to the optimum result. In this study, using graphite dies, graphite punches and tungsten carbide punches, solid samples were produced, having a cylinder shape of $\varnothing 4.00 \mathrm{~mm} \times 4.00 \mathrm{~mm}$. Several properties of the solid Ti and 90Ti10Sn samples, such as density, hardness and the microstructures, were examined, and these showed that good results have been obtained.
\end{abstract}

\section{Introduction}

In general, demands on micro-electromechanical systems (MEMS) and micro-products/parts are significantly increased where there is fast growth in applications in communication/telecommunications and automotive engineering. Wide applications are also seen in bio-medical technology, information technology and home-use electronics products. For instance, typical micro-parts which can be manufactured with micro-forming technology are the connecting pins that are widely used in computers, communication devices and other electronic products. As an example, Semiconductor Equipment and Materials International (SEMI) released its sales forecast for semiconductor equipment with a market value of $\$ 38$ billion in 2014 , which rose to approximately $\$ 44$ billion in 2015 , and enjoyed annual growth rates of approximately $19.3 \%$ and $15.2 \%$, respectively [1]. Due to this very high market value, it is very advantageous to improve the manufacturing process in order to reduce the cost and cycle time as well as improving the quality and accuracy of finished products/parts. Therefore, development in terms of fast-processes, high-volume production and low-cost manufacturing capabilities is needed.

According to Eriksson, Shen and Nygren, a development process using spark plasma sintering (SPS) with a Ti sample shows that the total time needed to complete the process with a good relative densification $(<99 \%)$ is approximately 10 minutes [2]. This was also tested by Chaudhary and Bauri

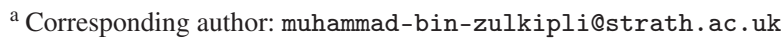

This is an Open Access article distributed under the terms of the Creative Commons Attribution License 4.0, which permits unrestricted use, distribution, and reproduction in any medium, provided the original work is properly cited. 
Table 1. Nominal chemistry and physical properties for Ti, 90Ti10Sn-P1 and 90Ti10Sn-P2.

\begin{tabular}{|l|l|c|c|}
\hline Powder Materials & Nominal Chemistry (wt. \%) & $\begin{array}{l}\text { Average Particle Size } \\
(\mu \mathbf{m})\end{array}$ & $\begin{array}{l}\text { Bulk Theory Density } \\
\left(\mathbf{g} / \mathbf{c m}^{\mathbf{3}}\right)\end{array}$ \\
\hline Ti & $\mathrm{Ti}-99.5 ;$ Others -0.5 & 45 & 4.51 \\
\hline 90Ti10Sn-P1 & $\mathrm{Ti}-90.0 ; \mathrm{Sn}-10.0$ & 27 & 4.77 \\
\hline 90Ti10Sn-P2 & $\mathrm{Ti}-90.0 ; \mathrm{Sn}-10.0$ & 27 & 4.75 \\
\hline
\end{tabular}

using the SPS process with Ti powder material, where the time needed to complete the process was in the range of five to 10 minutes [3]. For titanium alloys (Ti-6Al-4V), research conducted by Asaoka and Kon, also using the SPS process, showed that three minutes are required in order to complete the process however the porosity of the sample was within $30 \pm 3 \%$ [4]. Hence, using a concept of the process that combines micro-forming technology and fast powder-sintering enabled by simultaneously applying external electrical-field currents, offers the potentials of shortening the sintering time, addressing existing problems - especially in shortening the process chain - allowing for easier control of the microstructure of the part formed, reducing the forming pressure requirements, providing options to use different metal powders and combinations, improving the feasibility of forming micro-components with high-strength materials and reducing the influences from size effect in micro-forming, which all contribute to meeting the market's needs.

Lange stated that the densification process using the conventional powder-sintering method involves a coarsening or neck growth, which is a critical mechanism needed in order to achieve densification. This is caused by surface diffusion or evaporation/condensation. Thus, it is the reason why conventional powder sintering takes a long time to become completed [5]. Using the forming and electrical-field activated powder sintering process, the densification can be achieved more quickly, by deformation and breakage of the powder particles [6]. Based on this finding, it is important for the particle-changing process to be present in order to achieve satisfactory and quick densification of micro-parts [6].

The development of the tooling for the die set, also described in this article, provides a detailed report of the comparison features and the materials used. The summary of the cycle and temperature distribution during the process and the extent to which the die set can be used have also been discussed, which could contribute to optimised iteration of tool design in the future. Based on previous study, the material selected for the die set is usually graphite [7,8], which is an excellent choice in terms of working at high temperatures up to $2500^{\circ} \mathrm{C}$. The low mechanical strength of the graphite material at an elevated temperature is a major drawback, whereby a higher forming pressure cannot be applied during the electrical-field-activated sintering process.

\section{Experimental procedure}

Two kinds of powders were used as raw materials: Ti and 90Ti10Sn. For Ti, the average particle size of the powder material is $45 \mu \mathrm{m}$, it has a purity of $99.5 \%$ and is $4.51 \mathrm{~g} / \mathrm{cm}^{3}$ in theoretical bulk density. The 90Ti10Sn powder material is divided into two different theoretical bulk densities: 90Ti10Sn-P1 $\left(4.77 \mathrm{~g} / \mathrm{cm}^{3}\right)$ and 90Ti10Sn-P2 $\left(4.75 \mathrm{~g} / \mathrm{cm}^{3}\right)$. The average particle size $(27 \mu \mathrm{m})$, and nominal chemistry (90 wt. \% for $\mathrm{Ti}$ and $10 \mathrm{wt}$ \% for $\mathrm{Sn}$ ) for both powder materials are the same. These theoretical bulk densities were used as a reference to calculate the percentage relative density for each sample produced by the Ti and 90Ti10Sn powder materials as represented in Table 2. Meanwhile Table 1 shows the details of the powder materials used in this process.

The experiment was conducted using the Gleeble® 3800 thermal mechanical machine from Dynamic System Inc., USA. Figure 1 shows the arrangement of the tooling for the experiments. Each of the parameters used in the experiments, such as pressure, heating temperature, heating rate and holding time, was controlled automatically using a computer-controlled system (QuickSim ${ }^{\mathrm{TM}}$ software). In terms 


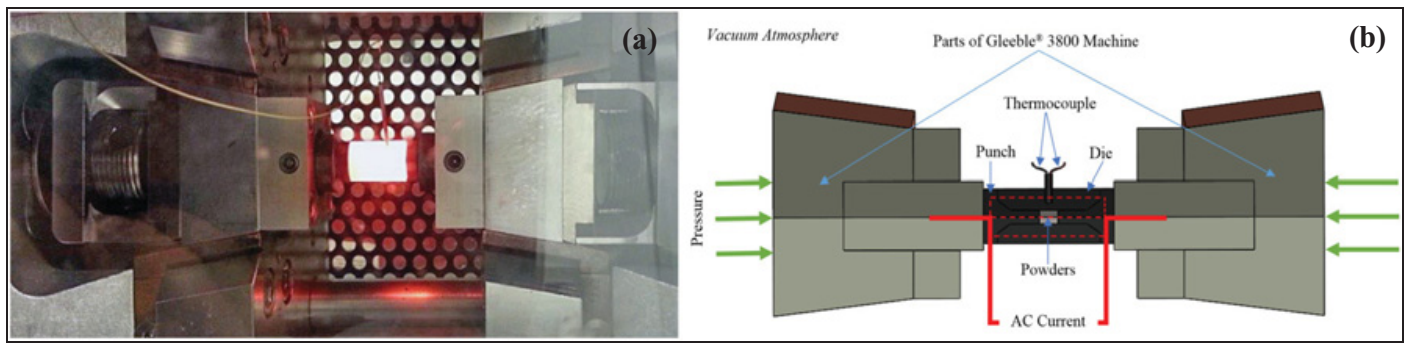

Figure 1. (a) Position of the die-set with powder in the Gleeble® 3800 machine; (b) schematic drawing of the machine.

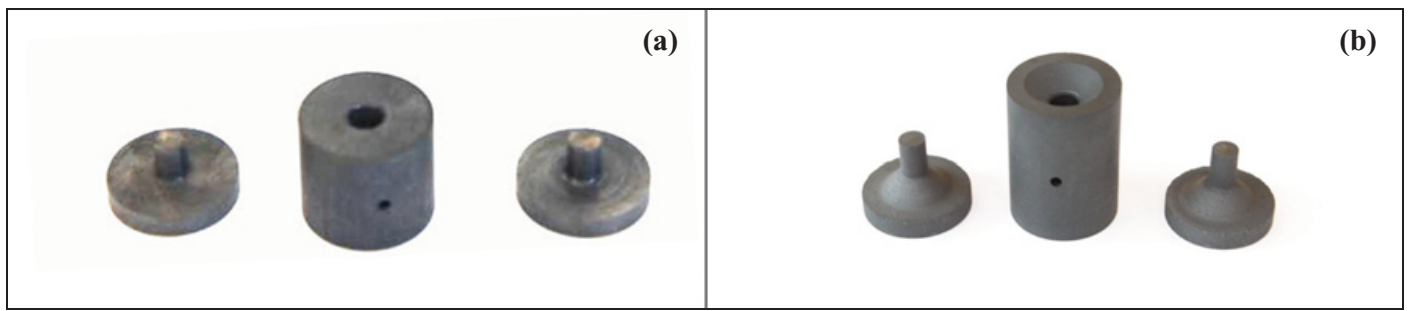

Figure 2. (a) Die-set A (previous design). (b) Die-set B (new design).

of the electrical field produced by the Gleeble ${ }^{\circledR} 3800$ machine, it has a high current $(3000 \sim 30000 \mathrm{~A})$ and low voltage $(3 \sim 10 \mathrm{~V})$. It is also capable of controlling the accuracy of the temperature up to $\pm 3{ }^{\circ} \mathrm{C}$.

In the experiments, there were two designs of die-set used: die-set $\mathrm{A}$ (previous design) and die-set B (new design). Die-set B is the optimisation design from die-set A. For die-set A, the material of the punch is tungsten carbide (Grade: VA80), and for die-set B, the material used is graphite (Grade: GV). For die-set B, all the punches and dies were made from graphite (Mersin 2333). The selection of the graphite material was made by considering that the value for the thermal expansion co-efficient of the punch and the die must be less than that of the powder material being tested. This is to prevent the punch, die or sample becoming stuck during the ejection process. The thermal expansion co-efficient for graphite is around 0.67 to $4.3 \mu$ strain $/{ }^{\circ} \mathrm{C}$ [9-11], while for titanium it is around 8.5 to $9.3 \mu$ strain $/{ }^{\circ} \mathrm{C}$, and for titanium alloy it is around 8.7 to $9.1 \mu$ strain $/{ }^{\circ} \mathrm{C}$ [12-14]. In addition, by using graphite, a higher sintering temperature can be used (up to $2500{ }^{\circ} \mathrm{C}$ or more). Large transitions are introduced for the modification of die-set A to die-set $\mathrm{B}$ in order to reduce the thermal stress concentration in the punch. Another positive contribution towards the punch modification is the concentrated heating at the punch nose, as a more uniform temperature distribution in the die's middle section occurred where the process's sintering samples are located, which could help to optimise the process of heating. Figure 2 shows the manufactured die-set for A (previous design) and B (new design). The final output samples were of cylindrical shape, of $4 \mathrm{~mm}$ diameter and $4 \mathrm{~mm}$ height.

Table 2 shows the processing details for Ti, 90Ti10Sn-P1 and 90Ti10Sn-P2. After the powder material had been weighed, it was carefully poured into the die, the latter having a hole diameter of $4.00 \mathrm{~mm}$, an outer diameter of $16.00 \mathrm{~mm}$ and a thickness of $12.00 \mathrm{~mm}$. Then, the die-set with the powder material was placed into the Gleeble ${ }^{\circledR} 3800$ machine with the thermocouple inserted into the small hole (cylindrical shape) at the centre body of the die $(\varnothing 1.60 \mathrm{~mm} \times$ length $-3.00 \sim 4.00 \mathrm{~mm})$. These conditions are necessary in order to accurately measure the heat at the nearest point to which the powder material has been sintered. Following this, the die-set with the powder material was heated promptly to a certain sintering temperature, according to Table 2 , within a vacuum atmosphere $\left(4.5 \times 10^{-1}\right.$ Torr $)$. A 
Table 2. Details of the process parameters, EDS and relative densities for Ti, 90Ti10Sn-P1 and 90Ti10Sn-P2.

\begin{tabular}{|c|c|c|c|c|c|c|c|c|}
\hline $\begin{array}{l}\text { Sample } \\
\text { Name } \\
\text { (\#) }\end{array}$ & $\begin{array}{l}\text { Pressure } \\
\text { Applied } \\
\text { (MPa) }\end{array}$ & $\begin{array}{l}\text { Heating } \\
\text { Rate } \\
\left({ }^{\circ} \mathbf{C} / \mathbf{s}\right)\end{array}$ & $\begin{array}{l}\text { Heating } \\
\text { Temp. } \\
\left({ }^{\circ} \mathbf{C}\right)\end{array}$ & $\begin{array}{l}\text { Holding } \\
\text { Time } \\
\text { (s) }\end{array}$ & $\begin{array}{l}\text { Total } \\
\text { Time } \\
\text { (s) }\end{array}$ & $\begin{array}{l}\text { EDS C* } \\
\text { at centre } \\
(\%)\end{array}$ & $\begin{array}{l}\text { EDS C* } \\
\text { at edge } \\
(\%)\end{array}$ & $\begin{array}{l}\text { Relative } \\
\text { Density } \\
(\%)\end{array}$ \\
\hline \multicolumn{9}{|c|}{ Titanium (Ti) $-45 \mu \mathrm{m} \mathrm{\&} 4.51 \mathrm{~g} / \mathrm{cm}^{3}$} \\
\hline Ti-1 & 75 & 50 & 700 & 2 & 119.0 & 3.12 & 4.82 & 92.24 \\
\hline Ti-2 & 75 & 50 & 1100 & 5 & 170.0 & 2.54 & 3.93 & 95.57 \\
\hline Ti-3 & 125 & 50 & 1100 & 5 & 170.0 & 3.64 & 4.73 & 96.23 \\
\hline Ti-4 & 125 & 100 & 1100 & 5 & 161.0 & 3.18 & 3.07 & 98.55 \\
\hline \multicolumn{9}{|c|}{ Titanium Alloy 1 (90Ti10Sn-P1) - $27 \mu \mathrm{m} \& 4.77 \mathrm{~g} / \mathrm{cm}^{3}$} \\
\hline P1-1 & 125 & 50 & 950 & 5 & 105.5 & 2.57 & 2.72 & 94.50 \\
\hline P1-2 & 125 & 50 & 1050 & 5 & 112.5 & 2.71 & 2.87 & 97.19 \\
\hline P1-3 & 125 & 50 & 1150 & 5 & 119.5 & 2.58 & 2.80 & 98.21 \\
\hline P1-4 & 125 & 25 & 1150 & 5 & 138.5 & 2.70 & 2.75 & 98.51 \\
\hline \multicolumn{9}{|c|}{ Titanium Alloy $2\left(90\right.$ Ti10Sn-P2) $-27 \mu \mathrm{m} \& 4.75 \mathrm{~g} / \mathrm{cm}^{3}$} \\
\hline P2-1 & 125 & 50 & 1050 & 5 & 112.5 & 3.72 & 3.48 & 97.72 \\
\hline P2-2 & 125 & 50 & 1150 & 5 & 119.5 & 3.08 & 2.97 & 97.63 \\
\hline P2-3 & 125 & 25 & 1150 & 5 & 138.5 & 3.30 & 3.51 & 98.49 \\
\hline P2-4 & 125 & 100 & 1150 & 5 & 110.0 & 3.40 & 3.25 & 98.33 \\
\hline
\end{tabular}

C*-Carbon.

high electrical current is then passed through the die-set and powder material, as illustrated in Fig. 1(b). Simultaneously, a certain pressure was applied to the upper and lower punches.

The results obtained from the experiments were analysed for their relative density (Sartorius YDK03) and the sample's surface microstructure - using a scanning electron microscope machine (SEM/EDS - HITACHI SU-6600) - and a chemical element weight percentage test was performed at the centre and edge of the sample using energy dispersive spectroscopy (EDS) facility. A nano-hardness (NanoTest Vantage) test was also done at the sintered neck of the sample.

\section{Results and discussion}

\subsection{Properties of the sintered samples}

The results for the relative densification and chemical element weight percentage of carbon (C) at the centre and edge for Ti, 90Ti10Sn-P1 and 90Ti10Sn-P2 can be found in Table 2. Ti shows a strong incremental value of relative density $(92.24-98.55 \%)$ directly proportional to the heating temperature and heating rate. For 90Ti10Sn-P1 (94.50-98.51\%) and 90Ti10Sn-P2 (97.63-98.49\%), according to optimum parameters obtained from $\mathrm{Ti}$ as a reference, by only changing the heating temperature and heating rate, the percentages of relative density also increase. Furthermore, nano-hardness testing has been applied to the Ti and 90Ti10Sn-P1 samples with 100 indentation (maximum load of $20.02 \mathrm{mN}$ ), which indicates $2.915 \mathrm{GPa}$ and $5.637 \mathrm{GPa}$ hardness values, respectively.

The presence of carbon at the centre and edge of the samples also represents a small amount of contamination. This is due to a drawback when using graphite die and punches where carbon at the punch nose and die wall can penetrate into a solidified sample during the high temperature sintering process. As a result, it is difficult to achieve a sample that is $100 \%$ free of contamination by other elements such as carbon, especially in the surfaces, when graphite die and punches are used.

\subsection{Microstructure of the formed samples}

Figure 3(a) shows a comparison between samples of Ti, 90Ti10Sn-P1 and 90Ti10Sn-P2, which indicates that the samples can be well sintered to dense solidity within a relatively short sintering time 


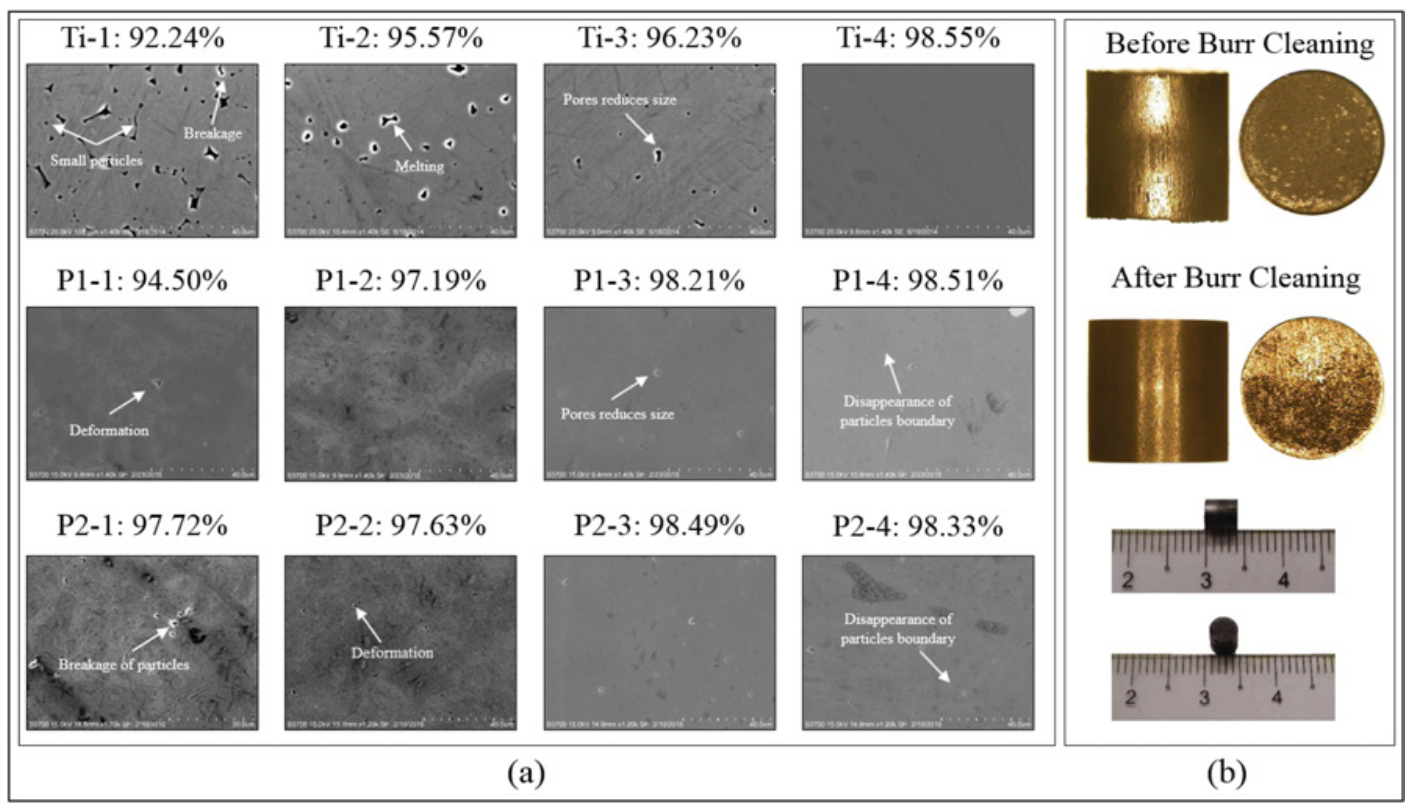

Figure 3. (a) SEM micrographs of formed samples Ti, 90Ti10Sn-P1 and 90Ti10Sn-P2, and (b) sample solidcylinders of $\varnothing 4.00 \mathrm{~mm} \times 4.00 \mathrm{~mm}$ : before burr-edge cleaning and after burr-edge cleaning.

( $<3$ minutes). The pores of the sample decrease as the heating temperature and heating rate rise, which accompanies densification of the sample. Also, no coarsening of grains accompanies the process of densification of the samples. In Fig. 3(a), the micrograph of Ti-1 shows that small particles break away from the large particle, which was constrained from moving. This process occurs in the other samples, which indicates an increase of contact areas as the densification value increases. The additional action from the pressure applied also helps the deformation and crushing of the particles, which can contribute to forcing the particles to touch each other during the strengthened sintering process until the pores become smaller and disappear, as seen in Fig. 3(a) for Ti-4, P1-4 and P2-3. This phenomenon supports the statement in Sect. 1 about the forming of the electrical densification process [6].

As shown in Fig. 3(b), the cleaning process needs to be done at the top and wall surface of the samples due to the sticking carbon element. Based on the Ti, 90Ti10Sn-P1 and 90Ti10Sn-P2 samples, the weight of the carbon sticking to the sample is in the range of $0.0007-0.0020 \mathrm{~g}$.

\subsection{Die material and die design}

Die-sets A and B for the sintering of Ti (die-set A), 90Ti10Sn-P1 (die-set B) and 90Ti10Sn-P2 (die-set B), show the heating to be uniform, as represented in Fig. 1(a). Die-set A can only be used, on average, up to six times due to the tendency of sticking between the punch and the die at high temperatures caused by different thermal expansions and retractions, as explained in Sect. 2. For die-set B, no issues were found during the ejection of the sample, and the die could be used repeatedly. Based on the observation on the die-sets tested, the crucial part that is most easily broken is the punch nose due to the many cycles of the process. On the other hand, a body of die-set B cannot be used once it is burnt due to concerns over performance ability.

There are several limitations when using die sets made of graphite. In terms of durability, graphite dies need to be cleaned after being used several times. This is because the powder material used melts 


\section{MATEC Web of Conferences}

and may become stuck onto the punch and die surfaces. A cleaning process needs to be introduced after several uses. The robustness to impact from a higher forming pressure on the graphite die-sets is a key weakness due to low mechanical strength at elevated temperature during the forming and sintering process.

\section{Conclusions}

From the work completed in this study, the following conclusion can be drawn:

1. The optimum parameters for the Ti sample with a $98.55 \%$ relative density were: a pressure of $125 \mathrm{MPa}$, a heating temperature of $1100^{\circ} \mathrm{C}$, a heating rate of $100^{\circ} \mathrm{C} / \mathrm{s}$ and a holding time of $5 \mathrm{~s}$.

2. On the other hand, for the 90Ti10Sn-P1 and 90Ti10Sn-P2 samples, which can reach relative densities of up to $98.51 \%$ and $98.49 \%$, respectively, the optimum parameters were: a pressure of $125 \mathrm{MPa}$, a heating temperature of $1150^{\circ} \mathrm{C}$, a heating rate of $25^{\circ} \mathrm{C} / \mathrm{s}$, and a holding time of $5 \mathrm{~s}$.

3. This efficient process has the potential to save time compared to the conventional process. It also suggests that, although with different bulk theory densities, the similar process parameters can be used to obtain higher densification.

4. Changes of the particles in terms of deformation and breaking are crucial in the process of achieving the densification, which differs from a conventional sintering process.

The authors would like to acknowledge the funding support from European Commission through FP7 FOF MicroFAST Project (GA No. 608720). The authors would specially thank Prof. Jianguo Lin and his colleagues in Imperial College London for providing the Gleeble machine for conducting the experiments and for their kind support through the experiments, and thank Micro-FAST project partners for supplying the powder materials for the experiments.

\section{References}

[1] D. Geiger and D. Tracy, Semiconductor Equipment Sales Forecast: \$38 Billion in 2014 to Nearly \$44 Billion in 2015 ISEMI.ORG

[2] M. Eriksson, Z. Shen, and M. Nygren, Powder Metall., 48, no. 3, pp. 231-236 (2005)

[3] R. Chaudhari and R. Bauri, Metallogr. Microstruct. Anal., 3, no. 1, pp. 30-35 (2014)

[4] M. Kon, L.M. Hirakata, and K. Asaoka, J. Biomed. Mater. Res. B. Appl. Biomater., 68, no. 1, pp. 88-93 (Jan. 2004)

[5] F.F. Lange, J. Eur. Ceram. Soc., 28, no. 7, pp. 1509-1516 (Jan. 2008)

[6] K. Huang, Y. Yang, Y. Qin, and G. Yang, Mater. Manuf. Process., 28, no. 2, pp. 183-188 (Feb. 2013)

[7] R. Nicula, F. Turquier, M. Stir, V.Y. Kodash, J.R. Groza, and E. Burkel, J. Alloys Compd., 434-435, pp. 319-323 (May 2007)

[8] H.W. Zhang, R. Gopalan, T. Mukai, and K. Hono, Scr. Mater., 53, no. 7, pp. 863-868 (Oct. 2005)

[9] G.W.C. Kaye and T.H. Laby, Table of Physical \& Chemical Constants, 15th ed. Longman, NY, US (1986)

[10] D.W. Richerson, Modern Ceramic Engineering, 2nd ed. Macrel Dekker, New York, USA (1992)

[11] ASM, ASM Engineered Materials Handbook: Ceramics and Glasses, 4. ASM International, Metals Park, Ohio 44073, USA (1991)

[12] ASM, Guide to Materials Engineering Data and Information. ASM International, Metal Parks, Ohio 44073, USA (1986)

[13] J. Emsley, Nature's Building Blocks. Oxford University Press, Oxford, UK (2002)

[14] G. Hammond and C. Jones, Inventory of Carbon and Energy (ICE). Dept. of Mechanical Engineering, University of Bath, UK (2006) 